\title{
Role of Bcl-2 on drug resistance in breast cancer polyploidy-induced spindle poisons
}

\author{
BIBO YUAN ${ }^{1}$, JUAN HAO $^{2 *}$, QIAN ZHANG $^{3 *}$, YAN WANG $^{4 *}$ and $\mathrm{YU} \mathrm{ZHU}^{5}$ \\ ${ }^{1}$ Department of Gynecology and Obstetrics, Tianjin Medical University General Hospital, Tianjin 300052; \\ ${ }^{2}$ Department of Gynecology and Obstetrics, Peking University People's Hospital, Beijing 100044; \\ ${ }^{3}$ Department of Gynecology and Obstetrics, Tianjin Metabolic Diseases Hospital and Tianjin Institute of Endocrinology, \\ Tianjin Medical University, Tianjin 300070; ${ }^{4}$ Department of Gynecology and Obstetrics, Tianjin Jinghai Hospital, \\ Tianjin 301600; ${ }^{5}$ Department of Clinical Laboratory, Tianjin Huanhu Hospital, Tianjin 300350, P.R. China
}

Received February 1, 2019; Accepted October 22, 2019

DOI: $10.3892 / \mathrm{ol} .2020 .11256$

\begin{abstract}
Spindle poisons are chemotherapeutic drugs used in the treatment of malignant tumors; however, numerous patients develop resistance following chemotherapy. The present study aimed to induce polyploidy in breast cancer cells using the spindle poison nocodazole to investigate the mechanism of polyploid-induced tumor resistance. It was revealed that the spindle poison nocodazole induced apoptosis in HCC1806 cells but also induced polyploidy in MDA-MB-231 cells. The drug sensitivities of the polyploid MDA-MB-231 cells to paclitaxel, docetaxel, epirubicin, 5-fluorouracil and oxaliplatin were lower than those of the original tumor cells; however, the polyploid MDA-MB-231 cells were more sensitive to etoposide than the original tumor cells. The expression of F-box and WD repeat domain containing 7 (FBW7) was decreased, while the expression of MCL1 apoptosis regulator BCL2 family member (MCL-1) and Bcl-2 was increased, and caspase-3/9 and Bax were not expressed in MDA-MB-231 cells. The resistance to docetaxel and etoposide was reversed, but the sensitivity of paclitaxel was not changed following Bcl-2 silencing. The formation of polyploidy in tumors may be one of the molecular mechanisms underlying tumor resistance to spindle poisons. Expression of the Bcl-2 family members, for example FBW7 and MCL-1, plays a key role in apoptosis and the cell escape process that forms polyploid cells. However, Bcl-2 silencing
\end{abstract}

Correspondence to: Professor Bibo Yuan, Department of Gynecology and Obstetrics, Tianjin Medical University General Hospital, 154 Anshan Road, Tianjin 300052, P.R. China

E-mail: yuanbibotj@163.com

Professor Yu Zhu, Department of Clinical Laboratory, Tianjin Huanhu Hospital, 6 Jizhao Road, Tianjin 300350, P.R. China

E-mail: zhuyutj@126.com

*Contributed equally

Key words: polyploidy, spindle poisons, breast cancer, Bcl-2, drug resistance has different reversal effects on different anti-tumor drugs, which requires further investigation.

\section{Introduction}

Tumor chemotherapy is an important part of the comprehensive treatment for solid tumors (1). Paclitaxel, vincristine and other spindle poisons are widely used as first-line chemotherapy for various types of malignant tumor, such as breast cancer, cervical cancer and melanoma $(2,3)$. One of the important methods in treating cancer is inducing tumor cell death. In the clinical setting, it was observed that certain types of tumor are sensitive to this type of drug, and in such cases, the tumor tissue disappears following several cycles of chemotherapy $(4,5)$. However, more commonly, the tumor tissue is sensitive to the drug at the beginning of chemotherapy, but drug resistance eventually occurs, or the tumor tissue has no obvious response to this class of drugs (6). The latter two phenomena are the root cause of uncontrollable tumors and recurrence. Previous studies demonstrated that spindle poisons play a role in the induction of apoptosis in some cells $(2,7)$. However, certain cells do not undergo apoptosis when exposed to such drugs, and instead form polyploids. Polyploid tumors are extremely insensitive to common radiotherapy and chemotherapy options, and patients who have tumors with polyploid subclones have a worse prognosis $(8,9)$. Therefore, it was speculated that the formation of polyploids may be associated with tumor resistance.

For a number of years, research has focused on elucidating the molecular mechanism underlying tumor resistance, and numerous theories and potential mechanisms have been proposed; however, a resolution to this clinical issue has not yet been identified $(10,11)$. With continuous scientific development, it has become apparent that the causes of tumor resistance are multi-faceted. In addition to the current multi-drug resistance genes that are known, it was speculated that the formation of polyploids is likely to lead to resistance to spindle poisons and is an important cause of tumor drug resistance after use (10-12); however, a mechanism for this possible drug resistance has not yet been proposed. The phenomenon of tumor-forming polyploidy induced by spindle poison was used 
as a basis for the design of the present study. MDA-MB-231 cells were treated with the spindle poison nocodazole in order to establish a stable polyploid cell model. Subsequently, the sensitivity of chemotherapeutic drugs on polyploid and original tumors was investigated with the aim of elucidating the association between polyploid formation and tumor resistance, and to attempt to determine the molecular mechanism underlying polyploidy occurrence through in-depth analyses. A potential intervention point/method to address such resistance was identified, and a new strategy was proposed in the present study to prevent the occurrence of tumor resistance by inhibiting the formation of polyploid subclones.

\section{Materials and methods}

Cell lines and cell culture. For routine culturing, human breast cancer HCC1806 and MDA-MB-231 cells were obtained from China Infrastructure of Cell Line Resources, Institute of Basic Medical Sciences, Chinese Academy of Medical Sciences, and MDA-MB-231 polyploid cells (T-MDA-MB-231) were established in the laboratory. These cells were cultured in RPMI-1640 medium (Corning Inc.) containing 10\% newborn calf serum (Corning, Inc.) at $37^{\circ} \mathrm{C}$ and $5 \% \mathrm{CO}_{2}$. Cells in the logarithmic growth phase were used in the subsequent experiments.

Nocodazole drug induction assay. HCC1806 and MDAMB-231 cells $\left(1 \times 10^{6}\right.$ cells $\left./ \mathrm{ml}\right)$ were inoculated into $10-\mathrm{cm}$ culture dishes for $24 \mathrm{~h}$ and then the antibiotic-free RPMI 1640 medium was replaced fresh antibiotic-free RPMI-1640 medium with $10 \%$ fetal bovine serum (Corning, Inc.) containing nocodazole (Sigma-Aldrich; Merk KGaA). The base volume was $10 \mathrm{ml}$, and the final concentration of nocodazole was $100 \mu \mathrm{g} / \mathrm{l}$; the cells were treated for $0-72 \mathrm{~h}$ at $37^{\circ} \mathrm{C}$, and $3 \mathrm{dupli}-$ cate wells were examined for each group. The morphological changes in the HCC1806 and MDA-MB-231 cells prior to and following nocodazole treatment were observed under a light microscope at x200 magnification and images were captured at randomly selected fields.

Cell cycle analysis. MDA-MB-231 and HCC1806 cells were treated with $100 \mu \mathrm{g} / 1$ nocodazole for $0,6,12,24,48$ or $72 \mathrm{~h}$, and the cells were trypsinized by $0.25 \%$ trypsin, collected, fixed in $70 \%$ cold ethanol and incubated overnight at $4^{\circ} \mathrm{C}$. After centrifuging for $5 \mathrm{~min}$ at $300 \mathrm{x} \mathrm{g}$ and at room temperature, the ethanol was discarded, and the pellets were washed with PBS and incubated with $100 \mathrm{ng} / \mathrm{l} \mathrm{RNase}$ for $37 \mathrm{~min}$ at $37^{\circ} \mathrm{C}$. A total of $500 \mu \mathrm{l}$ propidium iodide (PI; $2 \mu \mathrm{g} / \mathrm{ml}$ ) stain solution was added, and the cells were incubated at room temperature for $30 \mathrm{~min}$ in the dark prior to being counted $\left(1 \times 10^{6}\right.$ cells $\left./ \mathrm{ml}\right)$. The cell cycle $\left(\mathrm{G}_{0} / \mathrm{S}\right.$ or $\left.\mathrm{G}_{2} / \mathrm{M}\right)$ was detected via flow cytometry (FACSCanto II; BD Biosciences), and the percentages of diploid, tetraploid and octoploid cells in the total cell population were determined by the FACSDiva software (version 8.0.1; BD Biosciences).

Flow cytometry sorting of polyploids. According to the results of the cell cycle assay, $100 \mu \mathrm{g} / 1$ nocodazole-treated MDA-MB231 cells were harvested at the point of maximal polyploid formation $(72 \mathrm{~h}$ ), and the cells were resuspended in RPMI 1640 medium at $4^{\circ} \mathrm{C}$ at a concentration of $1 \times 10^{6}$ cells $/ \mathrm{ml}$.
Subsequently, Hoechst $33342(5 \mu \mathrm{g} / \mathrm{ml})$ was added, and the cells were incubated at $37^{\circ} \mathrm{C}$ for $90 \mathrm{~min}$. After centrifuging at $300 \mathrm{x} \mathrm{g}$ for $10 \mathrm{~min}$ at $4^{\circ} \mathrm{C}$, the supernatant was discarded, and the cells were resuspended in pre-chilled Hanks' Balanced Salt Solution (Beyotime Institute of Biotechnology). A total of $500 \mu \mathrm{l} \mathrm{PI}(2 \mu \mathrm{g} / \mathrm{ml})$ was then added to the solution prior to sieving using a 200-mesh nylon cell sieve. Flow cytometry (FACSCanto II) was used to obtain drug-treated polyploid cells (T-MDA-MB-231) using the FACSDiva software (version 8.0.1). After routine stable growth, polyploid cells in the logarithmic growth phase were subjected to secondary sorting using the same method. Subcloning of polyploid cells was performed by limiting dilution.

Apoptosis experiment. The present study aimed to compare the sensitivity of polyploid cells and their diploid parental cells to commonly used chemotherapeutic drugs. Therefore, representative drugs from different chemotherapeutic drug classes, paclitaxel and docetaxel (Jiangsu Hengrui Medicine Co., Ltd.), were used for the apoptosis experiments. MDA-MB-231 and T-MDA-MB-231 cells in the logarithmic growth phase $\left(5 \times 10^{5}\right.$ cells $\left./ \mathrm{ml}\right)$ were plated into 6 -well cell culture plates and cultured for $24 \mathrm{~h}$ at $37^{\circ} \mathrm{C}$ and $5 \% \mathrm{CO}_{2}$ using the $30 \%$ inhibitory concentration $\left(\mathrm{IC}_{30}\right)$ and the $60 \%$ inhibitory concentration $\left(\mathrm{IC}_{60}\right)$ of 0.66 and $2.50 \mu \mathrm{M}$ for paclitaxel and 3.48 and $12.10 \mu \mathrm{M}$ for docetaxel, respectively, to treat the MDA-MB-231 and T-MDA-MB-231 cells. After incubating for $72 \mathrm{~h}$ at $37^{\circ} \mathrm{C}$, the cells were centrifuged at $300 \mathrm{x}$ g for $4 \mathrm{~min}$ at $4^{\circ} \mathrm{C}$, and $5 \mu \mathrm{l}$ Annexin $\mathrm{V}$ and $10 \mu \mathrm{l}$ PI were added, followed by incubation for $15 \mathrm{~min}$ at room temperature in the dark. Apoptosis was subsequently detected by flow cytometry (FACSCanto II; excitation wavelength, $488 \mathrm{~nm}$ ) with the FACSDiva software (version 8.0.1).

MTT assay. T-MDA-MB-231 cells were seeded at $5 \times 10^{3}$ cells/well in 96-well plates using 2 and $4 \mu \mathrm{M}$ of the multi-kinase inhibitor sorafenib (Sigma-Aldrich; Merck $\mathrm{KGaA}$ ) alone or in combination with $100 \mu \mathrm{g} / \mathrm{l}$ nocodazole or $100 \mathrm{nmol} / \mathrm{l}$ paclitaxel for 48 and $72 \mathrm{~h}$, with 5 replicate wells per group; $4 \mu \mathrm{l}$ of a $5 \mathrm{~g} / \mathrm{l}$ MTT solution were added for $4 \mathrm{~h}$. At termination, the medium was removed from each well, and $200 \mu \mathrm{l}$ of dimethyl sulfoxide was added per well, followed by shaking until the crystals dissolved. The same method was applied to compare differences in the cell cytotoxicity of MDA-MB-231 and T-MDA-MB-231 cells treated with spindle poisons, paclitaxel $(0,0.39,0.78,1.56,3.125,6.25,12.5,25$ and $50 \mu \mathrm{M})$, docetaxel $(0,0.39,0.78,1.56,3.125,6.25,12.5$, 25 and $50 \mu \mathrm{M})$, epirubicin $(0,0.39,0.78,1.56,3.125,6.25$, 12.5, 25 and $50 \mu \mathrm{M}), 5$-fluorouracil (FU) $(0,0.78,1.56,3.125$, $6.25,12.5,25,50$ and $100 \mu \mathrm{M})$, oxaliplatin $(0,0.78,1.56,3.125$, $6.25,12.5,25,50$, and $100 \mu \mathrm{M})$ or etoposide $(0,0.0195,0.039$, $0.078,0.156,0.3125,0.625,1.25$ and $2.50 \mu \mathrm{M})$. Epirubicin was purchased from Pfizer Inc. 5-FU, oxaliplatin or etoposide were purchased from Jiangsu Hengrui Medicine Co., Ltd. Differences in the cytotoxicity of paclitaxel, docetaxel, epirubicin, 5-FU, oxaliplatin or etoposide on T-MDA-MB-231 cells and MDA-MB-231 cells were also examined by MTT assay. The absorbance value at $490 \mathrm{~nm}$ of each well was measured using a microplate reader with the tecan i-control 2.0 software, and the cytotoxicity rate was calculated as $1-\mathrm{A}_{490} \mathrm{drug}$ group $/ \mathrm{A}_{490}$ control group $\mathrm{x} 100 \%$. 
Western blotting. MDA-MB-231 and T-MDA-MB-231 cells $\left(3 \times 10^{5}\right)$ were treated with $100 \mu \mathrm{g} / 1$ nocodazole for $48 \mathrm{~h}$ and then digested and centrifuged at $300 \mathrm{x}$ g for $5 \mathrm{~min}$ at $4^{\circ} \mathrm{C}$ and collected. Subsequently, the cells were lysed using radioimmunoprecipitation assay lysis buffer (Beyotime Institute of Biotechnology), and the cell lysates (total protein) were collected by centrifugation at $16,000 \mathrm{x}$ g for $10 \mathrm{~min}$ at $4^{\circ} \mathrm{C}$. Protein concentration was determined using a BCA kit (Beyotime Institute of Biotechnology). For each sample, $100 \mu \mathrm{g}$ of total cell protein per lane was separated via SDS-PAGE (12\% gel) and then transferred to a polyvinylidene fluoride membrane. Following blocking with 5\% skimmed milk at $4^{\circ} \mathrm{C}$ for $1 \mathrm{~h}$, the membrane was incubated with primary monoclonal antibodies (all purchased from Abcam) against F-box and WD repeat domain containing 7 (FBW7; 1:1,500; cat. no. ab109617), MCL1 apoptosis regulator BCL2 family member (MCL-1; 1:1,500; cat. no. ab32087), Bcl-2 (1:1,500; cat. no. ab185002), Bax (1:1,500; cat. no. ab232479), caspase-3 (1:1,500; cat. no. ab179517), caspase-9 (1:1,500; cat. no. ab2013) and $\beta$-actin $\left(1: 5,000\right.$; cat. no. ab179467) overnight at $4^{\circ} \mathrm{C}$. The membrane was washed three times to remove the primary antibody, and then incubated with goat anti-rabbit-horseradish peroxidase-labeled secondary antibody $(1: 1,000$; cat. no. ab6721; Abcam) for $1 \mathrm{~h}$ at room temperature. After washing three times, Immobilon Western chemiluminescent horseradish peroxidase substrate (EMD Millipore) was used to develop the membranes. The experiment was performed three times and visualized by Image J (National Institutes of Health; version 1.8.0).

Reverse transcription-quantitative PCR (RT-qPCR). MDAMB-231 and T-MDA-MB-231 cells were digested, centrifuged at $300 \mathrm{x} \mathrm{g}$ for $5 \mathrm{~min}$ at $4^{\circ} \mathrm{C}$ and collected. Total RNA was extracted using TRIzol ${ }^{\circledR}$ (Invitrogen; Thermo Fisher Scientific, Inc.), and cDNA was obtained via the BeyoRT ${ }^{\mathrm{TM}}$ RT kit (Beyotime Institute of Biotechnology), according to the manufacturer's protocol. qPCR was subsequently performed using BeyoFast $^{\mathrm{TM}}$ SYBR Green qPCR Mix kit (Beyotime Institute of Biotechnology) according to the manufacturer's protocol. The following primer pairs were used: Bcl-2 forward, 5'-ATGTGT GTGGAGAGCGTCAA-3' (140 bp) and reverse, 5'-GCCGTA CAGTTCCACAAAGG-3' (140 bp); and GAPDH forward, 5'-GAAGGTGAAGGTCGGAGTC-3' (225 bp) and reverse, 5'-GAAGATGGTGATGGGATTTC-3' (225 bp). For each reaction, pre-denaturation was performed at $95^{\circ} \mathrm{C}$ for $7 \mathrm{~min}$, followed by 35 cycles of denaturation at $95^{\circ} \mathrm{C}$ for $40 \mathrm{sec}$, annealing at $56^{\circ} \mathrm{C}$ for $40 \mathrm{sec}$, and extension at $72^{\circ} \mathrm{C}$ for $40 \mathrm{sec}$; and a final extension was performed at $72^{\circ} \mathrm{C}$ for $10 \mathrm{~min}$. GAPDH was used as an internal reference to calculate the relative expression of the $\mathrm{Bcl}-2$ gene via the $2^{-\Delta \Delta \mathrm{Cq}}$ method (13).

RNA interference. T-MDA-MB231 cells were transfected using Lipofectamine ${ }^{\mathrm{TM}} 2000$ (Invitrogen; Thermo Fisher Scientific, Inc.) according to the manufacturer's protocol, and MDA-MB231 cells were used as controls. Logarithmic growth phase T-MDA-MB231 cells at $1.5 \times 10^{5}$ cells per well were added to 6-well plates and incubated for $24 \mathrm{~h}$, after which Lipofectamine $^{\mathrm{TM}} 2000$ diluted in Opti-MEMI (Corning; Thermo Fisher Scientific, Inc.) was added at $50 \mu \mathrm{l} /$ well and mixed at room temperature for $5 \mathrm{~min}$. After $5 \mathrm{~min}, 100 \mu \mathrm{l}$ of liposomes (Invitrogen; Thermo Fisher Scientific Inc.) and Bcl-2 small interfering (si) RNA (forward, 5'-UGUGGAUGA CUGAGUACCUGA-3'; reverse, 5'-UCAGGUACUCAGUCA UCCACAGG-3') or control siRNA (AATTCTCCGAACGTG TCACGTCCTGTCTC) were purchase from Ambion (Thermo Fisher Scientific, Inc.) and incubated at room temperature for $20 \mathrm{~min}$. The liposome-siRNA complexes were added to the cells and then incubated at $37^{\circ} \mathrm{C}$ for $6 \mathrm{~h}$, at which time the media was replaced with fresh RPMI-1640 medium with $10 \%$ fetal bovine serum to continue the culture. The mRNA expression of Bcl-2 in T-MDA-MB-231 cells was detected by RT-qPCR as aforementioned, $72 \mathrm{~h}$ following siRNA transfection.

Statistical analysis. The statistical analyses were performed using SPSS software (version 17.0; SPSS, Inc.). Data are expressed as the mean \pm standard deviation from at least three separate experiments. Experimental results were assessed using one-way analysis of variance and SNK-q post hoc tests. $\mathrm{P}<0.05$ was considered to indicate a statistically significant difference. GraphPad Prism software (version 5.0; GraphPad Software, Inc.) was used to calculate the inhibitory concentrations.

\section{Results}

Nocodazole induces apoptosis in HCC1806 cells and polyploidy in $M D A-M B-231$ cells. A final nocodazole concentration of $100 \mathrm{ng} / \mathrm{ml}$ was used in the present study as it has been demonstrated that $100 \mathrm{ng} / \mathrm{ml}$ could induce polyploid $(14,15)$ After nocodazole was applied to MDA-MB-231 and HCC1806 cells for $24 \mathrm{~h}$, the cells began to appear rounded, and after $48 \mathrm{~h}$, the cells were all rounded. However, with prolonged exposure for $72 \mathrm{~h}$ to nocodazole, the HCC1806 cells exhibited typical apoptotic morphological changes; the cell volume gradually decreased, the cells became deformed and floated, their nuclei shrank, and apoptotic bodies formed. Fragmentation was gradually increased, and after $72 \mathrm{~h}$, apoptotic bodies were widespread. However, the MDA-MB-231 cells exhibited increased cell volume over time with drug exposure, and typical polyploid morphological changes were apparent, such as gradually increasing nuclei. After $72 \mathrm{~h}$, the polyploid appearance was prevalent (Fig. 1A).

In order to further verify the responses of MDA-MB-231 and HCC1806 breast cancer cells to nocodazole in the present study, samples of the two cell lines were analyzed by flow cytometry in the present study. After HCC1806 cells were treated with nocodazole for $6 \mathrm{~h}$, the percentage of $G_{2} / M$ phase cells increased, and the proportion of sub- $\mathrm{G}_{1}$ phase cells gradually increased. For MDA-MB-231 cells treated with nocodazole for 6,12 and $24 \mathrm{~h}$, the percentages of cells in the sub- $\mathrm{G}_{1}$ and $\mathrm{G}_{2} / \mathrm{M}$ phases were the same as those of $\mathrm{HCC} 1806$ cells, but the percentage of cells in the $G_{1} / S / G_{2} / M$ phase increased after $36 \mathrm{~h}$, and body (tetraploid and octoploid) cell formation increased significantly (Fig. 1B). These experiments indicated that nocodazole can induce apoptosis in HCC1806 cells but instead induces polyploidy in MDA-MB-231 cells.

The western blot analysis revealed that, compared with the control group, HCC1806 cells expressed caspase-9 and caspase- 3 after $24 \mathrm{~h}$ of incubation, indicating that nocodazole induced apoptosis in HCC1806 cells. The 

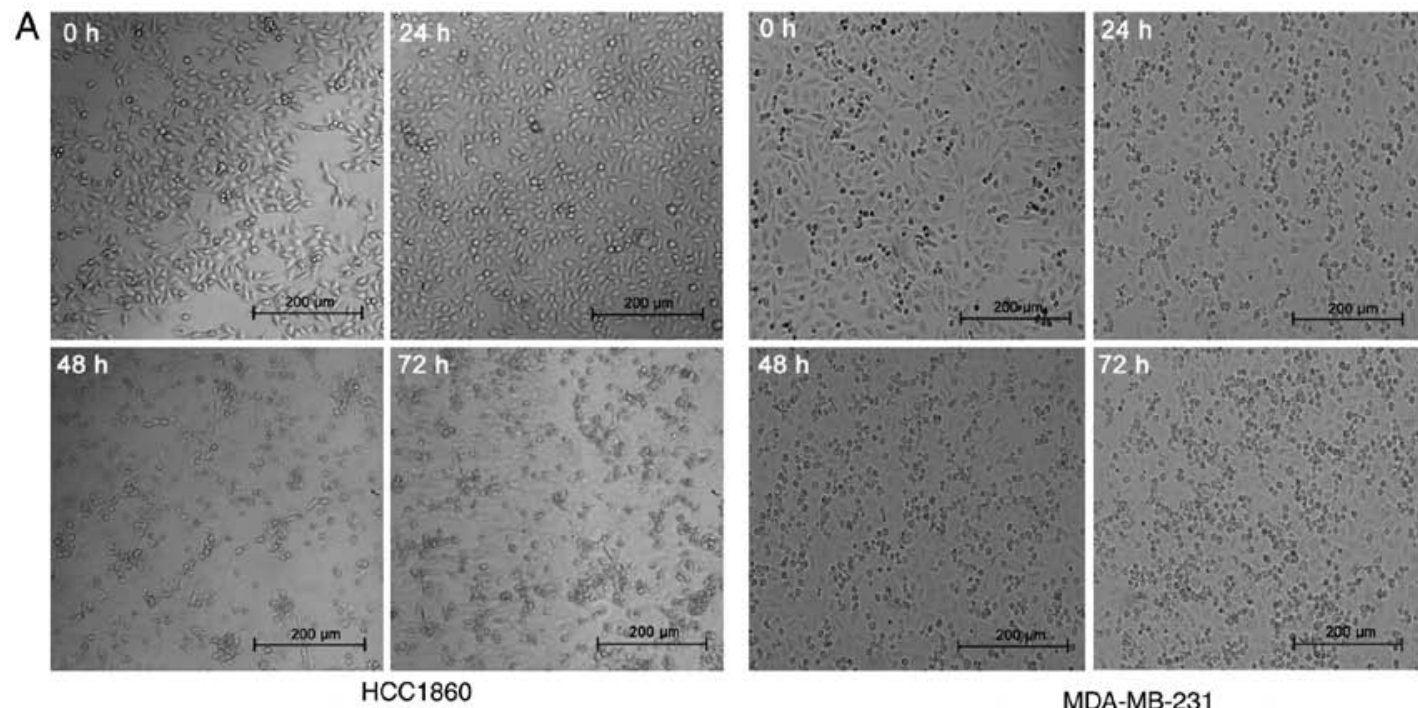

B
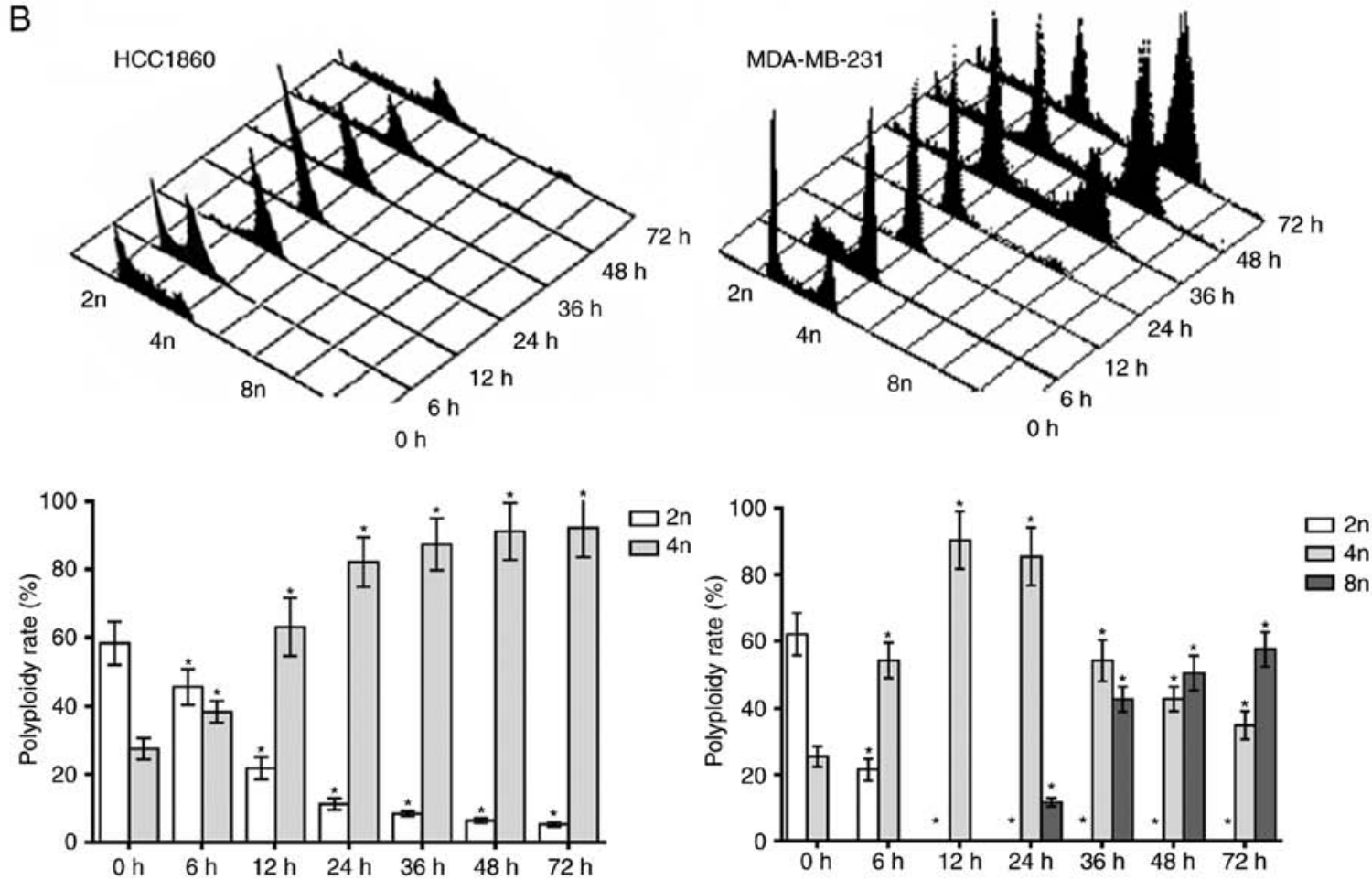

Figure 1. Different effect of nocodazole on HCC1806 and MDA-MB-231 cells. (A) The different morphological changes of HCC1806 and MDA-MB-231 cells treated with nocodazole at $0,24,48$ and $72 \mathrm{~h}$. (B) The different effects of nocodazole on polyploidy in HCC1806 and MDA-MB-231 cells. "P $<0.05$ vs. the $0 \mathrm{~h}$ group.

expression of caspase-9, caspase-3 and Bax was not detected in MDA-MB-231 cells. However, the Bax protein was continuously expressed in HCC1806 cells. In MDA-MB-231 cells, the expression of Bcl-2 increased significantly until $36 \mathrm{~h}$, and its expression levels were significantly different. Bcl-2 was also expressed in HCC1806 cells, and its expression increased after $36 \mathrm{~h}$ (Fig. 2). These experiments indicated that an increasing Bcl-2 in HCC1806 cells promoted apoptosis following treatment with nocodazole, while the high expression of Bcl-2 in MDA-MB-231 cells inhibited apoptosis and formed polyploid cells. High expression levels of Bcl-2 inhibit nocodazole-induced apoptosis in breast cancer cells and may be one of the primary molecular mechanisms underlying polyploid formation.
Effect of polyploid MDA-MB-231 on chemosensitivity. The appearance and polyploid certification of MDA-MB-231 parent cells and T-MDA-MB-231 polyploid cells is presented in Fig. 3A and B, viewed under a light microscope at X200 magnification and flow cytometry. Meanwhile, there was a slower rate of cytotoxicity in T-MDA-MB-231 cells, demonstrated by the MTT assay (Fig. 3C). The MTT assay results also revealed that T-MDA-MB-231 cells were less sensitive to paclitaxel, docetaxel, vincristine, oxaliplatin, 5-FU and epirubicin than MDA-MB-231 cells (all $\mathrm{P}<0.05$ ). However, T-MDA-MB-231 polyploid cells were more sensitive to etoposide (Fig. 3D). The flow cytometry results revealed that following treatment with paclitaxel and docetaxel at $\mathrm{IC}_{30}, \mathrm{IC}_{50}$ and $\mathrm{IC}_{60}$ for $72 \mathrm{~h}$, the survival rates of the polyploid T-MDA-MB-231 cells were higher than those of the 

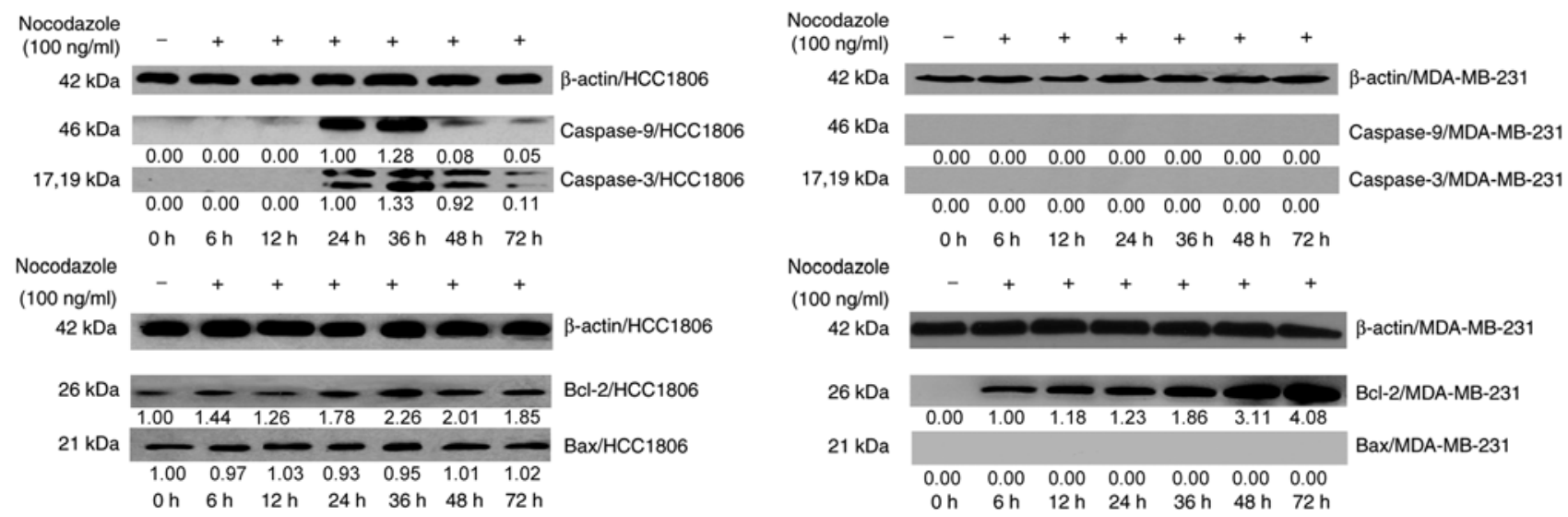

Figure 2. Effect of nocodazole on the expression of apoptosis-associated genes in HCC1806 and MDA-MB-231 cells. The western blotting results demonstrated that the effect of nocodazole on the expression of caspase-3/9, Bcl-2 and Bax in HCC1806 cells and MDA-MB-231 cells. $\beta$-actin was used as internal control.

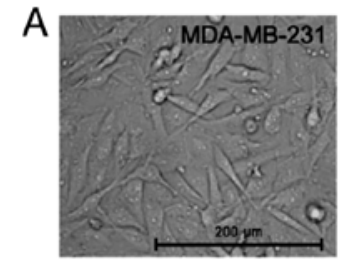

$\mathrm{D} \square$ MDA-MB-231
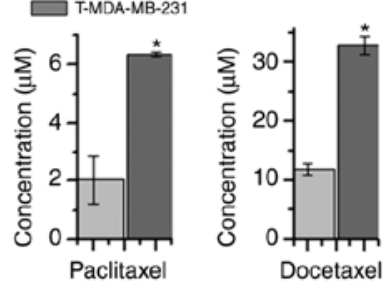

E
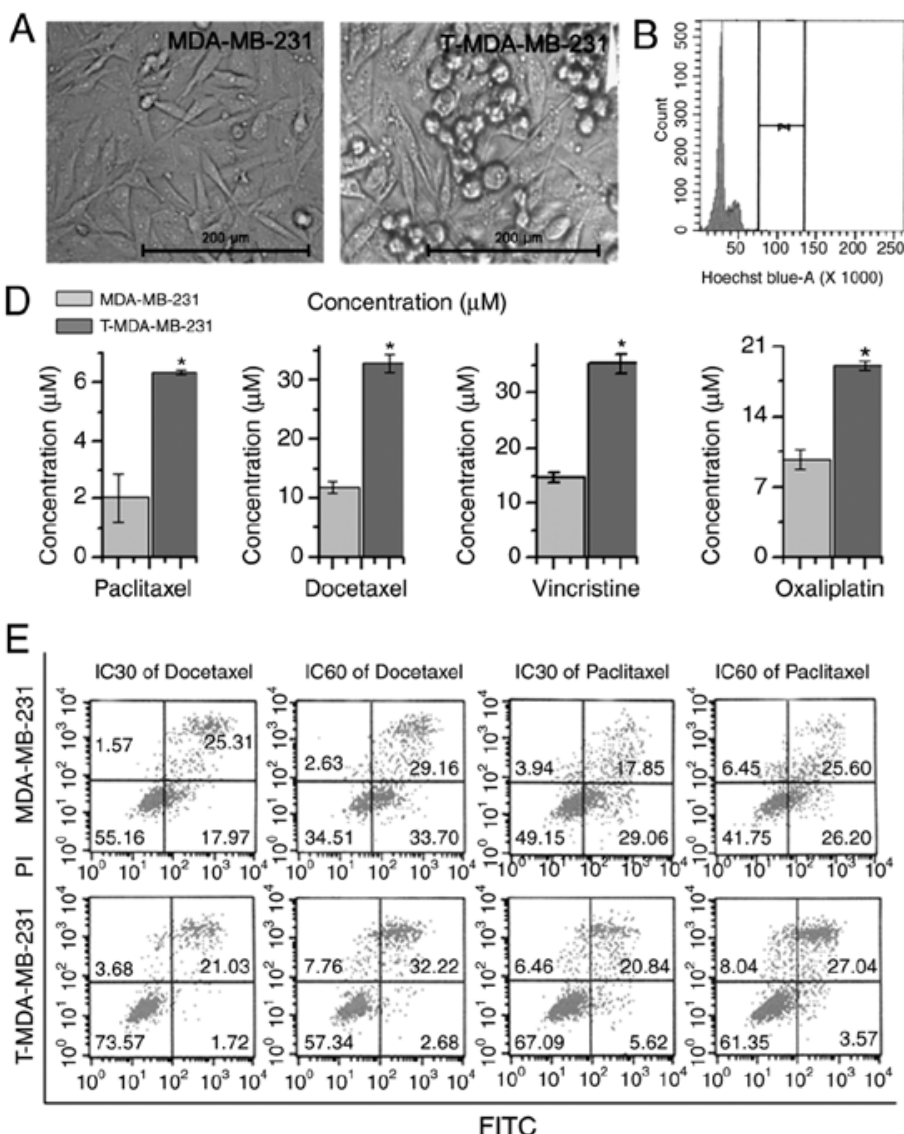
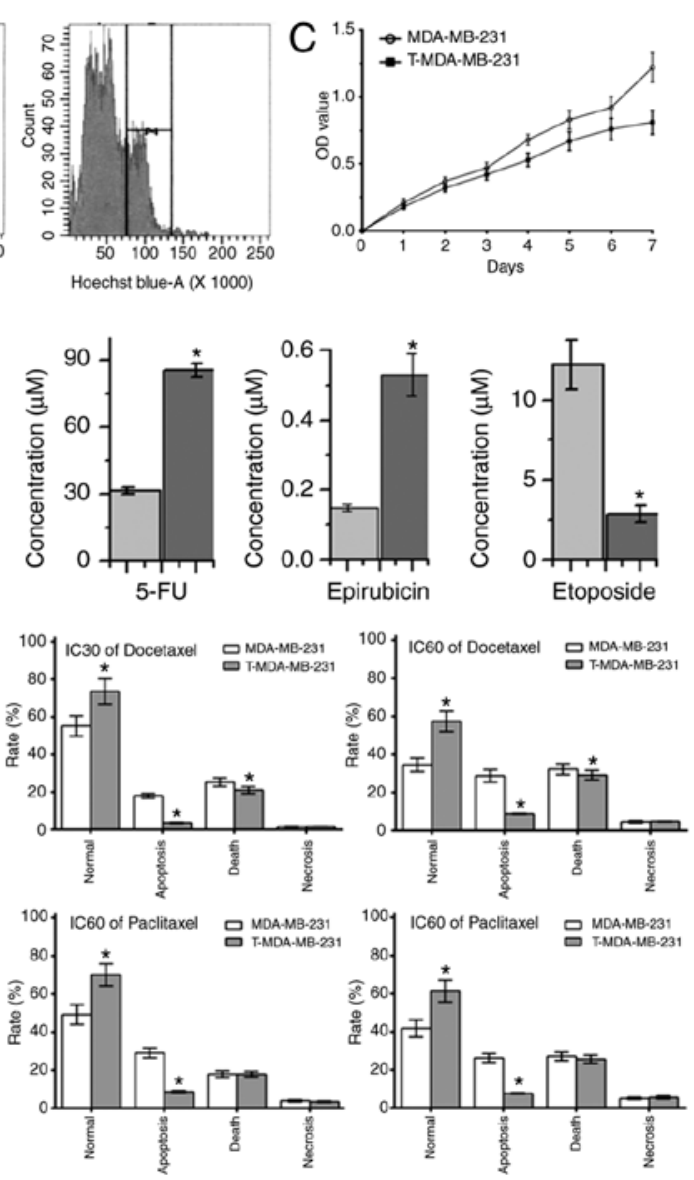

Figure 3. Effect of polyploid MDA-MB-231 on chemosensitivity. (A) The appearance of MDA-MB-231 parent cells and T-MDA-MB-231 polyploid cells. (B) The flow cytometry results demonstrated that there were polyploid T-MDA-MB-231 cells. (C) The proliferation of MDA-MB-231 parent cells and T-MDA-MB-231 polyploid cells. (D) The half maximal inhibitor concentration of paclitaxel, docetaxel, vincristine, oxaliplatin, 5-FU, epirubicin and etoposide in MDA-MB-231 parent cells and T-MDA-MB-231 polyploid cells. (E) The apoptosis of MDA-MB-231 parent cells and T-MDA-MB-231 polyploid cells induced by docetaxel and paclitaxel. ${ }^{*} \mathrm{P}<0.05$ vs. the MDA-MB-231 group. $\mathrm{FU}$, fluorouracil; $\mathrm{IC}_{30}, 30 \%$ inhibitory concentration; $\mathrm{IC}_{60}$, $60 \%$ inhibitory concentration; PI, propidium iodide.

parental MDA-MB-231 cells. The proportion of cells in early apoptosis was also lower in polyploid cells (Fig. 3E), indicating that polyploid tumors are more resistant to these anticancer drugs.

Role of the Bcl-2 protein family in polyploidy-induced tumor resistance. The RT-qPCR results revealed that the relative expression of Bcl-2 mRNA in T-MDA-MB-231 polyploid cells was significantly higher than that of the MDA-MB-231 parental cells. After silencing the expression of Bcl-2 mRNA in T-MDA-MB-231 cells using siRNA technology, the relative expression decreased significantly $(\mathrm{P}<0.05$; Fig. $4 \mathrm{~A})$ but was not significantly different to the expression levels 

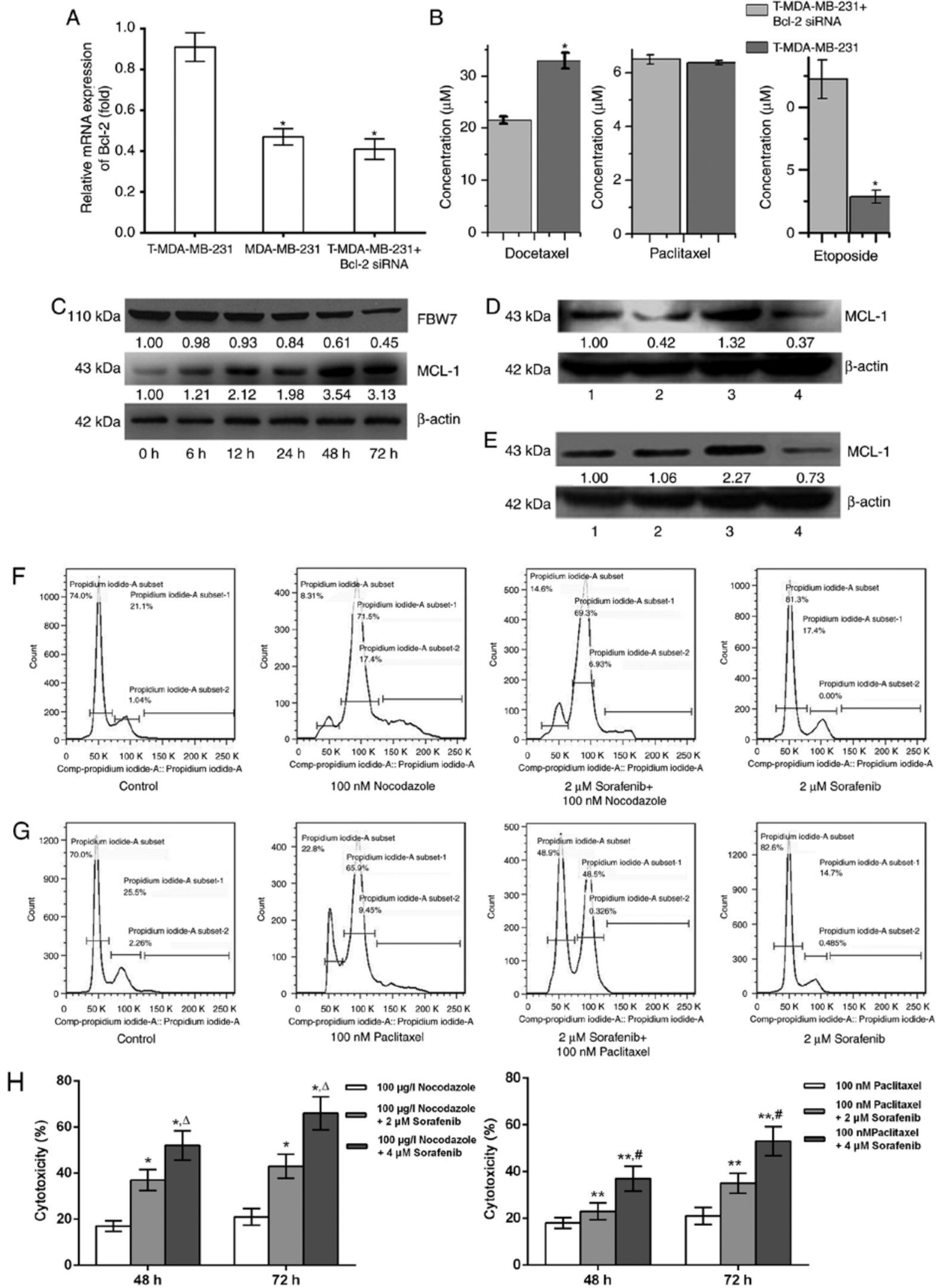

Figure 4. Role of the Bcl-2 protein family in polyploidy-induced tumor resistance in MDA-MB-231. (A) The relative mRNA expression of Bcl-2 of T-MDA-MB-231 cells, MDA-MB-231 parental cells and T-MDA-MB-231 cells following Bcl-2 silencing. (B) The half maximal inhibitory concentration of docetaxel, paclitaxel and etoposide for T-MDA-MB-231 cells with or without Bcl-2 silencing. (C) The protein expression of FBW7 and MCL-1 in MDA-MB-231 cells at different time points. (D) The protein expression of MCL-1 protein in MDA-MB-231 cells following treatment with nocodazole and sorafenib. $\beta$-actin was used as internal control. 1, control; $2,2 \mu \mathrm{M}$ sorafenib $+100 \mu \mathrm{g} / 1$ nocodazole; $3,100 \mu \mathrm{g} / 1$ nocodazole; $4,2 \mu \mathrm{M}$ sorafenib. (E) The protein expression of MCL-1 protein in MDA-MB-231 cells following treatment with paclitaxel and sorafenib. $\beta$-actin was used as an internal control. 1, control; $2,2 \mu \mathrm{M}$ sorafenib+ $100 \mathrm{nM}$ paclitaxel; 3, $100 \mathrm{nM}$ paclitaxel; 4, $2 \mu \mathrm{M}$ sorafenib. (F and G) The effect of ploidy on treatment with nocodazole, sorafenib, paclitaxel and sorafenib in the MDA-MB-231 cells. (H) The effect of sorafenib on the cytotoxicity of MDA-MB-231 at 48 and $72 \mathrm{~h} .{ }^{*} \mathrm{P}<0.05 \mathrm{vs.} 100 \mu \mathrm{g} / 1$ Nocodazole group; ${ }^{\Delta} \mathrm{P}<0.05$ vs. $100 \mu \mathrm{g} / 1$ Nocodazole $+2 \mu \mathrm{M}$ Sorafenib group; ${ }^{* *} \mathrm{P}<0.05$ vs. $100 \mathrm{nM}$ Paclitaxel group; $\mathrm{P}<0.05$ vs. $100 \mathrm{nM}$ Paclitaxel+ $2 \mu \mathrm{M}$ Sorafenib group. 
of the MDA-MB-231 parental cells. Following the silencing of Bcl-2 expression, mRNA was downregulated, the $\mathrm{IC}_{50}$ of docetaxel for T-MDA-MB-231 polyploid cells was significantly decreased, and the $\mathrm{IC}_{50}$ of etoposide was significantly increased; however, Bcl-2 silencing had no significant effect on the paclitaxel $\mathrm{IC}_{50}$ (Fig. $4 \mathrm{~B}$ ). These results indicated that the higher expression of $\mathrm{Bcl}-2$ in polyploidy cells plays a key role in the process by which cells escape apoptosis and further form polyploid cells, but has different effects on anti-tumor drugs with different mechanisms.

MCL-1 is an important anti-apoptotic protein in the Bcl-2 family, and it may play an important role in polyploidy resistance (16). With the prolonged nocodazole treatment time, expression of the FBW7 protein was decreased in MDA-MB-231 cells, while expression of MCL-1 was increased (Fig. 4C). The present study observed that after $48 \mathrm{~h}$ of treatment, the expression of MCL-1 was decreased and demonstrated by comparing the nocodazole+sorafenib group with the nocodazole group, and the paclitaxel+sorafenib group with the paclitaxel group in MDA-MB-231. At $48 \mathrm{~h}$, with sorafenib, expression of the MCL-1 protein was decreased, the number of diploid cells was increased, and the number of polyploid cells was decreased in MDA-MB-231 cells (Fig. 4D and E). There was an increase in diploid and decrease in polyploid cells in the nocodazole+sorafenib and sorafenib groups compared with the nocodazole group. There was a similar effect of ploidy in the nocodazole+sorafenib, paclitaxel+sorafenib and sorafenib groups, which polyploid was downregulated after sorafenib treating cells for 48 and $72 \mathrm{~h}$ (Fig. 4F and G), indicating that the combination of sorafenib and single-purpose spindle poisons can increase drug sensitivity and be used to reverse polyploid resistance, the occurrence of which may be associated with the regulation of MCL-1 protein expression and the cell cycle. The present study tested different concentrations of nocodazole and sorafenib and it was concluded that $100 \mu \mathrm{g} / 1$ nocodazole $+4 \mu \mathrm{M}$ sorafenib may be the best option by increasing cytotoxicity (Fig. 4H).

\section{Discussion}

At present, paclitaxel, vincristine and other spindle poisons are the first-line chemotherapy options for the majority of solid tumors, such as breast and ovarian cancer $(17,18)$. These drugs affect the structure and function of spindles during the process of mitosis in tumor cells, destroying the kinetochore and affecting the adhesion of the tube and the integrity of the mitotic apparatus to prevent normal splitting of the chromosome centromere, which is originally placed in the center of the equatorial plate $(19,20)$. Consequently, the chromosome cohort cannot be normally separated from the two poles of the spindle, and the spindle assembly checkpoint is activated. Under normal conditions, if the cell damage cannot be repaired, then the cells are unable to undergo mitosis, thereby initiating the apoptotic pathway and inducing apoptosis to achieve the ultimate goal of tumor cell death (21-24). However, certain cells ignore the spindle structure that is formed during mitosis, and in the case of functional disruption, the nucleus does not divide prior to entering the next cell cycle, forming polyploid tumor cells, which enhances resistance to chemotherapeutic drugs (25-27).
Nocodazole is responsible for inducing cell cycle arrest in the $\mathrm{G}_{2} / \mathrm{M}$ phase (28-30). Nocodazole interferes with the cell microtubules to form a spindle, which blocks cell division (7). The results of the present study demonstrated that nocodazole had a significant effect on the cell cycle, and $\mathrm{G}_{2} / \mathrm{M}$ phase arrest occurred following induction in MDA-MB-231 cells; however, the cells did not completely exit mitosis or activate apoptosis and instead entered the next cell cycle. The human breast cancer MDA-MB-231 cells were polyploidized, with typical polyploid morphological changes such as cell volume increase and nuclear enlargement observed. At present, the occurrence of drug resistance following the polyploidization of tumor cells is controversial. Castedo et al (31) reported that polyploid tumors exhibit significant resistance to cisplatin and camptothecin. Havas et al (32) demonstrated that cells were more sensitive to chemotherapeutic drugs following polyploidization. The present study revealed that polyploid tumor cells induced by spindle poisons were less sensitive to paclitaxel, docetaxel, vincristine, oxaliplatin, 5-FU and epirubicin than the original tumor cells. In addition, the results indicated that induced polyploid cells are relatively resistant to the majority of commonly used chemotherapeutic drugs and relatively sensitive to the topoisomerase II inhibitor etoposide, which not only validates the genetic instability of polyploid cells but also suggests that induced polyploid cells are likely to be a key problem in drug resistance during tumor treatment. It was hypothesized that there may be an especial mechanism underlying topoisomerase II inhibitors, for example, etoposide for polyploid breast cancer, which is different with other drugs such as paclitaxel and docetaxel. Therefore, the present study further investigated the specific molecular mechanism underlying polyploid cell resistance.

Nocodazole did not produce polyploidy in HCC1806 cells. MDA-MB-231 and HCC1806 cells have distinct p53 mutations that occur in response to spindle poisons, and both have complete spindle assembly checkpoints (33). MDA-MB-231 cells are characterized by polypoloid formation, and HCC1806 cells are characterized by apoptosis, meaning that their differential responses to nocodazole may be associated with inhibition of the apoptotic pathway. In order to further investigate whether the apoptotic pathway is involved in the formation of polyploid tumor cells induced by nocodazole, expression of the apoptotic pathway proteins Bcl-2 and Bax in nocodazole-induced polyploid tumors cells was investigated using two strains treated with the drug. Human breast cancer cells with different responses were studied: MDA-MB-231 cells were characterized by the formation of polyploid cells, and HCC1806 cells were characterized by apoptosis. Whether key proteins of the apoptosis pathway, Bcl-2 and Bax, were involved in the mechanism of polyploid tumor formation was preliminarily investigated.

The flow cytometry analysis revealed that the percentage of HCC1806 cells in the $\mathrm{G}_{2} / \mathrm{M}$ phase increased following nocodazole treatment for $6 \mathrm{~h}$, and the subdiploid peak (sub- $\mathrm{G}_{1}$ phase), also called the 'apoptosis peak', was increased at 36 and $48 \mathrm{~h}$ compared with $0 \mathrm{~h}$. Changes in the percentages of MDA-MB-231 cells in the $\mathrm{G}_{2} / \mathrm{M}$ phase and sub- $\mathrm{G}_{1}$ phase following nocodazole treatment for 6,12 and $24 \mathrm{~h}$ were the same as those of the HCC1806 cells. However, as the cells were incubated with the drug for a prolonged period of time, the two human breast cancer cells exhibited different outcomes: 
HCC1806 cells exited mitosis and activated apoptosis, which then occurred, while MDA-MB-231 cells re-entered mitosis in the absence of a nucleus, with the next cell cycle forming tetraploids. Therefore, it can be suggested that the two breast cancer cells have a perfect spindle monitoring point, and the effect of nocodazole on the cell cycle of MDA-MB-231 and HCC180 cells is noteworthy. MDA-MB-231 cells may be inhibiting the apoptotic pathway in order to enter the next cell cycle to form polyploids; thus, cell cycle regulation abnormalities may allow the cells to escape the restriction point 'lock', a mitotic slip that leads to polyploidy (tetraploid production).

Inhibition of the apoptotic pathway is one of the major causes of polyploid tumor cell formation; the Bax-dependent mitochondrial membrane permeabilization pathway may play an important role in preventing polyploid cell formation, particularly in polyploid p53 mutants (34). Variations in p53 mutations in different cell lines are particularly important (35). In the present study, MDA-MB-231 and HCC1806 cells were selected as the p53 mutants, and both cell lines had different responses to the spindle poisons, despite both having had perfect spindle assembly checkpoint functions. Western blotting was used to detect associated proteins in the two cells. The expression of caspase- 9 and caspase- 3 was examined; both were observed in HCC1806 cells $24 \mathrm{~h}$ after drug treatment. Bcl-2 was also expressed in HCC1806 cells; after $24 \mathrm{~h}$, its expression increased. However, MDA-MB-231 cells were primarily polyploidized following incubation with nocodazole. The western blot analysis revealed that the overexpression of Bcl-2 with no expression of Bax, caspase- 9 and caspase-3. From these results, it can be suggested that nocodazole induces the mechanism by which MDA-MB-231 cells form polyploid tumor cells. Bcl-2, which is highly expressed in MDA-MB-231 cells, could possibly bind to another Bcl-2 to form a homodimer. The pro-apoptotic effect of the Bcl-2/Bax heterodimer would be counteracted, thereby preventing the apoptotic effect of $\mathrm{Bcl}-2$ and causing the formation of polyploid tumor cells.

In the present study, the mRNA expression levels of Bcl-2 were detected in MDA-MB-231 parental cells and T-MDA-MB-231 polyploid cells. The results revealed that the mRNA expression of Bcl-2 in T-MDA-MB-231 polyploid cells was significantly increased, suggesting that overexpression of Bcl-2 is likely to be the key to polyploid cell resistance. siRNAs were also used to inhibit the expression of Bcl-2 mRNA in T-MDA-MB-231 polyploid cells in the present study. When Bcl-2 mRNA expression was downregulated, the $\mathrm{IC}_{50}$ of docetaxel for T-MDA-MB-231 polyploid cells was significantly decreased, and more polyploid cells were apoptotic, which significantly restored the sensitivity of polyploid cells to this chemotherapy drug. These results suggest that the resistance of polyploid tumors to certain chemotherapeutic drugs, such as docetaxel, may be significantly associated with high expression levels of Bcl-2. However, it was also observed that downregulating the expression of Bcl-2 mRNA in T-MDA-MB-231 polyploid cells

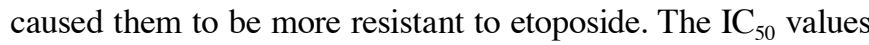
of the chemotherapy drugs evaluated revealed no significant changes for MDA-MB-231 cells when the expression of $\mathrm{Bcl}-2$ mRNA was downregulated in paclitaxel. The mechanism by which polyploids cause tumor resistance is complex and may involve a number of genes and their interactions. There may be different roles that Bcl-2 plays in different types of breast cancer, which further research will elucidate.

Studies have reported that MCL-1, an important antiapoptotic protein in the Bcl-2 family, is a key regulator of apoptosis that is induced by spindle poisons $(16,36)$. The results of the present study also revealed that expression of the FBW7 protein was decreased, and that of the MCL-1 protein was significantly increased following treatment with nocodazole for $48 \mathrm{~h}$, suggesting they may affect the formation of polyploidy in MDA-MB-231 cells. FBW7 degrades the downstream oncogenic protein MCL-1 by recognizing phosphorylation groups, promoting apoptosis and exerting anticancer effects (37-38). Therefore, it could be speculated that the lack of FBW7 due to low expression may cause decreased ubiquitination and degradation of MCL-1, resulting in the high levels of MCL-1 in MDA-MB-231cells, which may play a key role in the formation of polyploid tumors. MCL-1 is a potential target for reversing polyploid resistance. In the present study, it was observed that the polyploid and proliferation of MDA-MB-231 cells was decreased following treatment with the MCL-1 inhibitor sorafenib in, indicating the key role of the Bcl-2 family in breast cancer polyploidy.

The present study revealed that Bcl-2 protein likely inhibits apoptosis induced by spindle poisons in breast cancer MDA-MB-231 cells, which leads to polyploid cell tumor formation. Furthermore, polyploid tumor cell formation and tumor resistance are multifactorial, with numerous important molecular mechanisms. The present study investigated the molecular mechanisms underlying polyploidy and the association between polyploidy and tumor resistance in an attempt to ascertain potential interventional methods, which may lead to an improved understanding of polyploid tumor cell formation.

\section{Acknowledgements}

Not applicable.

\section{Funding}

The present study was funded by the National Natural Science Foundation of China (grant nos. 31501159 and 30872969), the Tianjin Public Health Key Research Project (grant no. 15KG108), the Tianjin Science and Technology Key Project on Chronic Disease Prevention and Treatment (grant no. 16ZXMJSY00020), the Special Program of Talent Development for Excellent Youth Scholars in Tianjin (grant no. TJTZJH-QNBJRC-2-9) and the Tianjin 131 Creative Talents Cultivation Project (1st Class, 2016), the Science and Technology Development Fund of Bengbu Medical College (grant no. BYKF1783) and The Fund of Tianjin People's Hospital (grant no. 2017YJ026).

\section{Availability of data and materials}

The datasets used and/or analyzed during the present study are available from the corresponding author on reasonable request.

\section{Authors' contributions}

BY and YZ contributed to the study conception and design. YZ wrote and revised the manuscript. JH, QZ and YW were 
responsible for the acquisition and analysis of data. All authors approved the final version of the manuscript.

\section{Ethics approval and consent to participate}

Not applicable.

\section{Patient consent for publication}

Not applicable.

\section{Competing interests}

The authors declare that they have no competing interests.

\section{References}

1. Fajka-Boja R, Marton A, Tóth A, Blazsó P, Tubak V, Bálint B Nagy I, Hegedús Z, Vizler $C$ and Katona RL: Increased insulin-like growth factor 1 production by polyploid adipose stem cells promotes growth of breast cancer cells. BMC Cancer 18: $872,2018$.

2. Yasuhira S, Shibazaki M, Nishiya $M$ and Maesawa $C$ : Paclitaxel-induced aberrant mitosis and mitotic slippage efficiently lead to proliferative death irrespective of canonical apoptosis and p53. Cell Cycle 15: 3268-3277, 2016.

3. Stojanovic N, Dekanic A, Paradzik M, Majhen D, Ferencak K, Ruscic J, Bardak I, Supina C, Tomicic MT, Christmann M, et al: Differential effects of integrin $\alpha v$ knockdown and cilengitide on sensitisation of triple-negative breast cancer and melanoma cells to microtubule poisons. Mol Pharmacol 94: 1334-1351, 2018.

4. Zhang W, Xu J, Ji D, Li Z, He W, Yang F, Lan H, Wang Y, Wu Z, Liu X, et al: CyclinG1 amplification enhances aurora kinase inhibitor-induced polyploid resistance and inhibition of Bcl-2 pathway reverses the resistance. Cell Physiol Biochem 43: 94-107, 2017.

5. Sharma S, Zeng JY, Zhuang CM, Zhou YQ, Yao HP, Hu X, Zhang R and Wang MH: Small-molecule inhibitor BMS-777607 induces breast cancer cell polyploidy with increased resistance to cytotoxic chemotherapy agents. Mol Cancer Ther 12: 725-736, 2013.

6. Gerashchenko BI, Salmina K, Eglitis J, Huna A, Grjunberga V and Erenpreisa J: Disentangling the aneuploidy and senescence paradoxes: A study of triploid breast cancers non-responsive to neoadjuvant therapy. Histochem Cell Biol 145: 497-508, 2016.

7. Han J, Wang QC, Zhu CC, Liu J, Zhang Y, Cui XS, Kim NH and Sun SC: Deoxynivalenol exposure induces autophagy/apoptosis and epigenetic modification changes during porcine oocyte maturation. Toxicol Appl Pharmacol 300: 70-76, 2016.

8. Li P, Zhou L, Liu X, Jin X, Zhao T, Ye F, Liu X, Hirayama R and Li Q: Mitotic DNA damages induced by carbon-ion radiation incur additional chromosomal breaks in polyploidy. Toxicol Lett 230: 36-47, 2014.

9. Nano M, Gemble S, Simon A, Pennetier C, Fraisier V, Marthiens V and Basto R: Cell-cycle asynchrony generates DNA damage at mitotic entry in polyploid cells. Curr Biol 29: 3937-3945.e7, 2019.

10. Hussain S, Singh A, Nazir SU, Tulsyan S, Khan A, Kumar R, Bashir N, Tanwar P and Mehrotra R: Cancer drug resistance: A fleet to conquer. J Cell Biochem 120: 14213-14225, 2019.

11. Müller A, Gillissen B, Richter A, Richter A, Chumduri C, Daniel PT and Scholz CW: Pan-class I PI3-kinase inhibitor BKM120 induces MEK1/2-dependent mitotic catastrophe in non-Hodgkin lymphoma leading to apoptosis or polyploidy determined by Bax/Bak and p53. Cell Death Dis 9: 384, 2018.

12. Mittal K, Donthamsetty S, Kaur R, Yang C, Gupta MV, Reid MD, Choi DH, Rida PCG and Aneja R: Multinucleated polyploidy drives resistance to Docetaxel chemotherapy in prostate cancer. Br J Cancer 116: 1186-1194, 2017.

13. Livak KJ and Schmittgen TD: Analysis of relative gene expres-sion data using real-time quantitative PCR and the 2(-Delta Delta C(T)) method. Methods 25: 402-408, 2001.

14. Hao J, Yuan BB, Xu YF, Yu J, Liu GY and Wang DH: Sensitivity to chemotherapeutic drugs of polyploid tumor cells induced by a spindle poison nocodazole. Zhonghua Zhong Liu Za Zhi 34 419-424, 2012 (In Chinese).
15. Inuzuka H, Shaik S, Onoyama I, Gao D, Tseng A, Maser RS, Zhai B, Wan L, Gutierrez A, Lau AW, et al: SCF(FBW7) regulates cellular apoptosis by targeting MCL1 for ubiquitylation and destruction. Nature 471: 104-109, 2011.

16. Srivastava S and Panda D: A centrosomal protein STARD9 promotes microtubule stability and regulates spindle microtubule dynamics. Cell Cycle 17: 2052-2068, 2018.

17. Chowdhury P, Nagesh PKB, Hatami E, Wagh S, Dan N, Tripathi MK, Khan S, Hafeez BB, Meibohm B, Chauhan SC, et al: Tannic acid-inspired paclitaxel nanoparticles for enhanced anticancer effects in breast cancer cells. J Colloid Interface Sci 535: 133-148, 2019.

18. Zeng F, Ju RJ, Liu L, Xie HJ, Mu LM and Lu WL: Efficacy in treating lung metastasis of invasive breast cancer with functional vincristine plus dasatinib liposomes. Pharmacology 101: 43-53, 2018.

19. Bosco B, Defant A, Messina A, Incitti T, Sighel D, Bozza A, Ciribilli Y, Inga A, Casarosa S and Mancini I: Synthesis of 2,6-diamino-substituted purine derivatives and evaluation of cell cycle arrest in breast and colorectal cancer cells. Molecules 23: E1996, 2018.

20. Jemaà M, Galluzzi L, Kepp O, Senovilla L, Brands M, Boemer U, Koppitz M, Lienau P, Prechtl S, Schulze V, et al: Characterization of novel MPS1 inhibitors with preclinical anticancer activity. Cell Death Differ 20: 1532-1545, 2013.

21. Krisenko MO, Cartagena A, Raman A and Geahlen RL: Nanomechanical property maps of breast cancer cells as determined by multiharmonic atomic force microscopy reveal Syk-dependent changes in microtubule stability mediated by MAP1B. Biochemistry 54: 60-68, 2015.

22. Choi HJ and Zhu BT: Role of cyclin B1/Cdc2 in mediating Bcl-XL phosphorylation and apoptotic cell death following nocodazole-induced mitotic arrest. Mol Carcinog 53: 125-137, 2014.

23. Wang Z, Chen X, Zhong MZ, Yang S, Zhou J, Klinkebiel DL, Karpf AR, Chen Y and Dong J: Cyclin-dependent kinase 1-mediated phosphorylation of YES links mitotic arrest and apoptosis during antitubulin chemotherapy. Cell Signal 52: 137-146, 2018.

24. Hsu CT, Huang YF, Hsieh CP, Wu CC and Shen TS: JNK inactivation induces polyploidy and drug-resistance in coronarin D-treated osteosarcoma cells. Molecules 23: E2121, 2018.

25. Horiuchi M, Kuga T, Saito Y, Nagano M, Adachi J, Tomonaga T, Yamaguchi $\mathrm{N}$ and Nakayama Y: The tyrosine kinase v-Src causes mitotic slippage by phosphorylating an inhibitory tyrosine residue of Cdk1. J Biol Chem 293: 15524-15537, 2018.

26. Vitale I, Manic G, Castedo M and Kroemer G: Caspase 2 in mitotic catastrophe: The terminator of aneuploid and tetraploid cells. Mol Cell Oncol 4: e1299274, 2017.

27. Zhou W, Xu J, Gelston E, Wu X, Zou Z, Wang B, Zeng Y, Wang H, Liu A, Xu L and Liu Q: Inhibition of Bcl-xL overcomes polyploidy resistance and leads to apoptotic cell death in acute myeloid leukemia cells. Oncotarget 6: 21557-21571, 2015.

28. Romanova LY, Mushinski F and Kovalchuk AL: Transcriptional activation of $\mathrm{p} 21 \mathrm{Waf} 1$ contributes to suppression of HR by p53 in response to replication arrest induced by camptothecin. Oncotarget 9: 25427-25440, 2018

29. Hsu CY, Lecland N, Pendaries V, Viodé C, Redoulès D, Paul C, Merdes A, Simon M and Bierkamp C: Stabilization of microtubules restores barrier function after cytokine-induced defects in reconstructed human epidermis. J Dermatol Sci 91: 87-96, 2018.

30. Dinić J, Ríos-Luci C, Karpaviciene I, Cikotiene I, Fernandes MX, Pešić M and Padrón JM: CKT0353, a novel microtubule targeting agent, overcomes paclitaxel induced resistance in cancer cells. Invest New Drugs Jun 8, 2019 (Epub ahead of print).

31. Castedo M, Coquelle A, Vivet S, Vitale I, Kauffmann A, Dessen P, Pequignot MO, Casares N, Valent A, Mouhamad S, et al: Apoptosis regulation in tetraploid cancer cells. EMBO J 25: 2584-2595, 2006.

32. Havas AP, Rodrigues KB, Bhakta A, Demirjian JA, Hahn S, Tran J, Scavello M, Tula-Sanchez AA, Zeng Y, Schmelz M and Smith CL: Belinostat and vincristine demonstrate mutually synergistic cytotoxicity associated with mitotic arrest and inhibition of polyploidy in a preclinical model of aggressive diffuse large B cell lymphoma. Cancer Biol Ther 17: 1240-1252, 2016.

33. Ferraz da Costa DC, Campos NPC, Santos RA, Guedes-da-Silva FH, Martins-Dinis MMDC, Zanphorlin L, Ramos C, Rangel LP and Silva JL: Resveratrol prevents p53 aggregation in vitro and in breast cancer cells. Oncotarget 9: 29112-29122, 2018. 
34. Zou X, Qu M, Fang F, Fan Z, Chen L, Yue W, Xie X and Pei X: Small molecule supplements improve cultured megakaryocyte polyploidization by modulating multiple cell cycle regulators. Biomed Res Int 2017: 2320519, 2017.

35. Dabiri Y, Abu El Maaty MA, Chan HY, Wölker J, Ott I, Wölfl S and Cheng X: p53-Dependent anti-proliferative and pro-apoptotic effects of a gold(I) N-heterocyclic carbene (NHC) complex in colorectal cancer cells. Front Oncol 9: 438, 2019.

36. Maity A, Majumdar S and Ghosh Dastidar S: Flexibility enables to discriminate between ligands: Lessons from structural ensembles of Bcl-xl and Mcl-1. Comput Biol Chem 77: 17-27, 2018.
37. Tong J, Tan S, Nikolovska-Coleska Z, Yu J, Zou F and Zhang L: FBW7-dependent Mcl-1 degradation mediates the anticancer effect of Hsp90 inhibitors. Mol Cancer Ther 16: 1979-1988, 2017.

38. Tong J, Tan S, Zou F, Yu J and Zhang L: FBW7 mutations mediate resistance of colorectal cancer to targeted therapies by blocking Mcl-1 degradation. Oncogene 36: 787-796, 2017.

(i) (9) This work is licensed under a Creative Commons Attribution-NonCommercial-NoDerivatives 4.0 International (CC BY-NC-ND 4.0) License. 